\title{
Os Functional Requirements for Bibliographic Records no contexto da Web Semântica: as contribuições de Paul Otlet
}

\author{
Functional Requirements for Bibliographic \\ Records in the context of the Semantic \\ Web: The contribution of Paul Otlet
}

Elisabete Gonçalves de SOUZA'

Darlene Alves BEZERRA'

\section{Resumo}

Este trabalho examina como o modelo conceitual Functional Requirements for Bibliographic Records se aproxima da noção de unidade documentária atribuída a Paul Otlet e presente no Traité de Documentation, cujos princípios são aplicados ao fundamentar as bases do Repertório Bibliográfico Universal. Em termos teóricos e metodológicos, trata-se de pesquisa exploratória de caráter histórico e documental, cujo objetivo é averiguar os pressupostos clássicos da representação e organização da informação, relacionando-os com o contexto da Web Semântica. Avança analisando os resultados de simulações acerca da aplicação dos Functional Requirements for Bibliographic Records no repositório Acesso Livre à Informação Científica da Empresa Brasileira de Pesquisa Agropecuária, de modo a ilustrar como as teses de Otlet se aplicam a essas ferramentas bibliográficas. Mostra as vantagens dos repositórios nos processos de modelagem, pois o formato Dublin Core permite a descrição de metadados usando linguagens como a Resource Description Framework, o que potencializa a recuperação de informações. Finaliza demonstrando como os princípios - monográfico, da continuidade e da pluralidade-, se expressam nas entidades do Grupo I do modelo conceitual Functional Requirements for Bibliographic Records, o que revela as afinidades metodológicas entre o modelo e as teses de Otlet. Ressalta que ações direcionadas no sentido de incentivar a descrição dos metadados bibliográficos em declarações em Resource Description Framework permitirá, num futuro bem próximo, que cada recurso seja identificado de forma pertinente por meio de um identificador universal - Uniform Resource Identifier -, possibilitando que os registros das bases de dados sejam interligados, permitindo ao usuário acesso a uma massa informacional há séculos estocada, tal como preconizou Otlet ao criar o Repertório Bibliográfico Universal.

Palavras-chave: Registros bibliográficos. Paul Otlet. Representação descritiva. Web Semântica.

\begin{abstract}
We examine how the conceptual model of Functional Requirements for Bibliographic Records is related to the notion of documentary unit attributed to Otlet and present in the Traite de Documentation, whose principles are applied to support the foundations of the Universal Bibliographic Repertory. In theoretical and methodological terms, this is an exploratory research with a historical and documentary nature that seeks to ascertain the classical assumptions of representation and organization of information and relate them to the context of the Semantic Web. We analyze the results of simulations of the application of the Functional Requirements for Bibliographic Records carried out in Acesso Livre à Informação Científica of Empresa Brasileira de Pesquisa Agropecuária to illustrate how Otlet's theses are applied to these digital bibliographies. We discuss the advantages of repositories for the modeling processes since

\footnotetext{
1 Universidade Federal Fluminense, Departamento de Ciência da Informação. R. Lara Vilela, 126, São Domingos, 24210-240, Niterói, RJ, Brasil. Correspondência para/Correspondence to: E.G. SOUZA. E-mail:<elisabetes.souza@gmail.com>.

Recebido em 31/3/2015, reapresentado em 29/6/2015 e aceito para publicação em 29/7/2015.
} 
the Dublin Core format allows the use of languages such as the Resource Description Frameworkfor the description of metadata, which enhances information retrieval. We conclude by demonstrating how the principles of monograph, continuity and plurality are expressed in the entities in Group I of Functional Requirements for Bibliographic Records conceptual model, which reveals methodological affinities between the model and Otlet's theses. We point out that actions directed towards encouraging the description of bibliographic metadata in Resource Description Framework statements will, in the near future, allow each resource to be identified in a meaningful way through a universal identifier - Uniform Resource Identifier-, allowing the database records to be interconnected and access to the user to a huge amount of stored information, as stated by Otlet when developing the Universal Bibliographic Repertory.

Keywords: Bibliographic record. Paul Otlet. Descriptive representation. Semantic web.

\section{Introdução}

A Web atual tem suas informações estruturadas em formatos lineares e textuais, o que dificulta a leitura pelas máquinas. Outro aspecto a ser considerado é que suas informações não são padronizadas e mudam com frequência, acarretando baixa precisão nos processos de recuperação da informação por computadores e agentes computacionais (softwares). Essa precariedade em sua estrutura levou Berners-Lee, o criador da Web, a pensar em uma nova geração da Web, denominada Web Semântica, cuja proposta é estruturar as páginas da Web (dados e metadados), atribuindo-Ihes significado, de modo que homens e máquinas possam recuperar os conteúdos dos sites e bases de dados.

No entanto, para que as páginas da Web tenham significado, "[...] os computadores devem ter acesso a coleções estruturadas de informações e a um conjunto de regras de inferência que os ajudem no processo de dedução automática" (Berners-Lee et al., 2001, p.2). Para que isso ocorra, os documentos devem ser descritos na linguagem Extensible Markup Language (XML), padrão proposto e homologado pelo World Wide Web Consortium (W3C) como mecanismo de codificação de metadados, cujas especificações formais incluem o modelo Resource Description Framework (RDF), que permite que a identificação de recursos seja feita por meio de identificadores da Web, denominados Uniform Resource Identifiers (URI), ou por um literal, como uma string: descrição dos recursos em termos de propriedades, na forma de triplas (sujeito, predicado e objeto) em que são descritos atributos e características que identificam os recursos.
No campo da catalogação descritiva, o primeiro movimento nessa direção foi a criação de um novo modelo conceitual - os Functional Requeriments for Bibliographic Records (FRBR, Requisitos Funcionais para Registros Bibliográficos) criado para estruturar os dados do "domínio bibliográfico" (International Federation of Library Associations and Institutions, 1998, 2009), reorganizando os seus elementos através da análise de entidades, atributos e relacionamentos, com o objetivo de proporcionar não só uma nova sintaxe à catalogação, mas principalmente uma nova semântica, identificando para cada entidade bibliográfica atributos únicos, capazes de individualizá-las para depois integrá-las através de ações de relacionamentos durante os processos de busca e recuperação, tomando por base as tarefas genéricas realizadas pelos usuários: encontrar, identificar, selecionar e obter.

Esse novo paradigma, anunciado pela International Federation of Library Associations and Institutions (IFLA), reatualiza sob novas bases tecnológicas os Princípios da Catalogação, além de retomar os fundamentos da Biblioteconomia conforme idealizaram Panizzi, Cutter e Lubetzky, cuja preocupação central sempre foi desenvolver"regras mais intuitivas que se tornassem compatíveis com o conhecimento dos usuários do catálogo" (Ortega, 2011, p.49). Significa que, ao aproximar a catalogação do paradigma da Web Semântica, a IFLA reconhece os limites do modelo anterior, cujo arcabouço teórico-metodológico, expresso pelas International Standard Bibliographic Description (ISBD), apesar do esforço em buscar sua consolidação ${ }^{2}$, mostrou-se acanhado frente às novas tecnologias de organização da informação e do conhecimento pautadas na tríade "entidades, atributos e relacionamentos". No entanto,

\footnotetext{
${ }^{2}$ A edição da ISBD consolidada, publicada em 2011, mescla os textos das sete ISBD especializadas (para livros, mapas, periódicos, gravações de som, arquivos de computador e outros recursos eletrônicos etc.) em um único texto. Além disso, nesta nova edição, a designação dos elementos obrigatórios da ISBD tem sido posta em conformidade com a terminologia do modelo conceitual FRBR. Disponível em:<http://www.ifla.org/publications/internationalstandard-bibliographic-description>. Acesso em: 17 mar. 2015.
} 
sabe-se que não se pode abrir mão dos padrões, daí a necessidade de adequá-los à dinâmica do mundo digital, cujo sucesso dos canais de comunicação depende do desenvolvimento de linguagens artificiais capazes de fazer a mediação entre os usuários e os conteúdos disponíveis na Web, de modo que essas informações sejam compreensíveis pelos agen-tes de softwares. É nessa direção que se presencia o avanço do modelo conceitual FRBR: de modelo conceitual do tipo E-R (entidade e relacionamento) para a metodologia orientada ao objeto: o FRBRoo.

Essa ação expressa o alinhamento dos dois modelos conceituais - o da IFLA, desenvolvido para o domínio bibliográfico, e o do CIDOC/CRM (Comitê Internacional de Documentação do Conselho Internacional de Museus). "O objetivo dessa parceria é contribuir para a solução do problema da interoperabilidade semântica entre as estruturas de dados utilizadas nas bibliotecas e museus" (International Council of Museums, 2009, online, tradução nossa) $)^{3}$.

No que diz respeito aos Princípios da Documentação idealizados por Paul Otlet e La Fontaine no sentido de pensar uma organização da informação capaz de recuperar todo o repertório bibliográfico universal, o novo modelo conceitual FRBR vem se mostrando compatível quando aplicado em repositórios, permitindo aos usuários dessas ferramentas recuperarem diferentes expressões e manifestações dos documentos, em sua totalidade ou em partes como, por exemplo, resumos de congressos, de teses etc. No entanto, por ter sido pensado prioritariamente para o universo das bibliotecas, sua discussão teórica no âmbito da documentação e das bibliografias ainda é muito recente.

A questão que mobilizou a realização da pesquisa foi a seguinte: o modelo conceitual FRBR se aproxima da noção de unidade documentária atribuída a Otlet e presente no Traité de Documentation (1934), cujos princípios são aplicados ao fundamentar as bases do Repertório Bibliográfico Universal (RBU)?

Os objetivos são: (a) entender os limites, as contradições e as possibilidades que tal aproximação traz para melhorar o desempenho das ferramentas bibliográficas, no sentido de que as novas tecnologias de descrição de conteúdos e de acesso potencializam os relacionamentos entre os recursos; (b) mostrar de que forma o novo modelo conceitual FRBR retoma os princípios da representação da informação e de que forma seus conceitos vêm sendo (re)aplicados no ambiente Web, à medida que o aprimoramento dos mecanismos de estruturação e descrição de dados oferece mais semântica e maior interoperabilidade às linguagens documentárias artificiais (códigos e tesauros).

Em termos teóricos e metodológicos, trata-se de pesquisa exploratória de caráter histórico e documental, pautada na leitura de textos de autores como Ortega (2011), Catarino e Souza (2012) e Marcondes (2013), que busca averiguar os pressupostos clássicos da representação da informação relacionando-os com o contexto da Web Semântica e, mais especificamente, com as bases teóricas que fundamentam os novos modelos conceituais para a representação de conteúdos em ambiente digital, como o modelo conceitual FRBR. Mostra como o novo paradigma da catalogação se aproxima do princípio da unidade documental tal como preconizou Paul Otlet ao idealizar a bibliografia universal: cada elemento intelectual de um documento, após ser seccionado de seu conjunto, é incorporado em um novo recurso (o RBU) cujo formato, pautado em normas e padrões de representação do conteúdo universal, permitiria a recuperação dos documentos em sua totalidade. Tal premissa vem inspirando os teóricos da W3C que veem na Internet e na filosofia dos dados abertos interligados (linked open data) o caminho para a consolidação desse sonho, cujas reminiscências se encontram no pensamento clássico de teóricos das áreas de biblioteconomia e documentação.

\section{Marco teórico}

Os debates sobre catálogo e catalogação ocorreram de forma significativa a partir do ano de 1831, quando o Museu Britânico contratou Antônio Panizzi (1797-1879) como bibliotecário assistente e o encarregou de coordenar os trabalhos de revisão do catálogo da instituição. Após diversas audiências, Panizzi, em 1839,

\footnotetext{
3 "[...] the International Working Group on FRBR/CIDOC CRM Harmonisation, that brings together representatives from both communities with the common goals of [...] aligning (possibly even merging) the two object-oriented models with the aim to contribute to the solution of the problem of semanticinteroperability between the documentation structures used for library and museum information".
} 
consegue convencer os membros da comissão de avaliação do Catálogo do Museu a aceitarem as 91 regras que formulara, nascendo assim os primeiros fundamentos da catalogação, dentre os quais se destaca a centralidade do conceito de obra.

O catálogo deve ser visto como um todo. O livro procurado por uma pessoa não é realmente, na maioria das vezes, o objeto de seu interesse, mas a obra nele contida; esta obra pode ser encontrada em outras edições, traduções, e versões, publicada sob diferentes nomes do autor e diferentes títulos e, consequentemente, para servir bem ao usuário, o Catálogo dever ser planejado para revelar todas as edições, versões, etc. das obras, bem como outras obras geneticamente relacionadas que existem na biblioteca (Fiuza, 1987, p.46, grifo do autor).

Os principais aspectos abordados nas 91 regras de catalogação dizem respeito às funções que um catálogo deve realizar para atingir seus objetivos e prover aos usuários o acesso ao documento desejado, conforme segue:

1) [o documento] deve ser considerado e representado no catálogo, não como uma entidade separada, mas como uma edição de determinada obra e de determinado autor;

2) todas as obras de um autor e suas edições devem ser entradas sob um nome definido, usualmente o nome original do autor, independentemente dos diferentes nomes que aparecem nas diferentes obras e edições;

3) todas as edições e traduções de uma obra, independentemente de seus títulos individuais, devem ter entradas sob seu título original, numa ordem prescrita (edições cronologicamente, traduções por língua etc.), de maneira que a pessoa em busca de um livro em particular, encontre-o junto com as outras edições, dando de importantes Instituições, como a Library of Congress (LC) e a International Federation of Library Associations and Institutions.

De acordo com a autora, a criação em 1969 da International Standard Bibliographic Description (ISDB) foi o avanço necessário para que a padronização atingisse a esfera internacional, sendo estabelecida uma sequência para a elaboração de metadados bibliográficos e sistematizadas oito áreas para a sua descrição, obedecendo a uma ordem e a uma pontuação fixa.

Diante da necessidade urgente de aperfeiçoar as normas descritivas, em 1978 o Anglo-American Cataloguing Rules (AACR2) é publicado segundo os novos critérios estabelecidos pelas ISBD. Esse código trouxe em sua estrutura uma inovação: pela primeira vez em noventa anos "um código de catalogação tem seu início pela descrição dos documentos para depois partir para os pontos de acesso" (Ortega, 2011, p.49).

A partir do novo código, a LC avançou em seu projeto de automação dos catálogos, criando o formato MARC (Machine Readable Cataloging). Ao longo das décadas de 1970 e 1980 o formato evoluiu, mas as discussões sobre os fundamentos da catalogação cessaram.

Conforme Ortega (2011, p.49) "o início da informatização dos processos de catalogação contribuiu para que a criação dos formatos de registro bibliográfico e a revisão dos códigos de catalogação não fossem acompanhadas, significativamente, por reflexões sobre princípios". Para autora, corroborando com Barbosa (1978), depois de Panizzi, Cutter e Lubetzky "[...] nada mais foi feito a favor de regras mais intuitivas que se tornassem compatíveis com o conhecimento dos usuários do catálogo" (Ortega, 2011, p.49).

Dos teóricos citados acima apenas Lubetzky (1898-2003) pôde analisar os impactos do uso dos computadores nos processos de catalogação. Para ele o advento do computador levou os bibliotecários a reconsiderar os objetivos da catalogação e, mais particularmente, os meios de atingi-los, mas isso não deveria significar um brusco abandono das ideias adotadas no passado (Lubetzky, 1979).

Para Lubetzky todo o esforço intelectual para fundamentar a catalogação não pode ser substituído pelas inovações tecnológicas que visam unicamente 
aperfeiçoar a maneira de confeccionar os registros. Mas elas devem ser incorporadas com vistas à melhoria das funções e objetivos dos processos biblioteconômicos

Passados dez anos da declaração de Lubetzky, a IFLA, frente aos avanços proporcionados pela tecnologia da Web, iniciou os estudos para a configuração dos novos princípios da catalogação, estudos esses que se expressaram na criação do modelo conceitual Functional Requirements for Bibliographic Records. O objetivo do modelo conceitual FRBR foi fornecer uma estrutura que identificasse e definisse com maior clareza as entidades de interesse dos usuários dos registros bibliográficos, seus atributos e tipos de relacionamentos. Na metodologia do modelo, a "entidade" é o objeto chave de interesse dos usuários, sendo obra a entidade central à qual todas as demais entidades (expressão, manifestação, item etc.) se referem.

Este estudo detém-se em discutir as entidades do Grupo 1 do modelo conceitual FRBR que compreendem os produtos dos esforços intelectuais e artísticos descritos nos registros bibliográficos, a saber: obra, expressão, manifestação e item. Essas entidades formam a base do modelo e de sua metodologia.

As entidades obra e expressão se referem ao conteúdo artístico e intelectual, sem deixar de lado o objeto físico sob o qual se materializam (livros impressos, digitais, registros iconográficos etc.), sendo essas entidades definidas como manifestação e item.

Ortega (2011) destaca como ponto relevante do modelo a possibilidade de apresentação dos registros bibliográficos segundo as entidades do Grupo I. Assim como as "manifestações" e as "expressões" de uma obra são agrupadas, é possível ao usuário, após uma busca, elencar todas as obras por meio dessas entidades e fazer a seleção a partir dos diversos itens que o acervo possui da mesma obra, como propôs Panizzi.

Indo nessa direção, Tillett (1988) ao analisar os fundamentos da catalogação, destaca as ideias de Panizzi e sua preocupação em estruturar o catálogo conceitualmente:

[...] Suas regras refletem uma estrutura conceitual baseada em registros únicos e completos para cada documento catalogado, e três tipos de referências cruzadas: 1) nome para nome, 2) nome para obra, e 3) obra para obra. A estrutura conceitual do catálogo era a mais econômica possível: registrar os documentos uma única vez e garantir o acesso às entidades bibliográficas através das referências [...] Com a evolução da catalogação outros pontos adicionais [conexões entre os registros] foram acrescidos e outros tipos de dispositivos de relação surgiram visando controlar os pontos de acesso como: os nomes de pessoas, de entidades coletivas, de assunto, entre outros (Tillett,1988, p.5, tradução nossa) ${ }^{4}$.

A tecnologia das fichas, concebidas segundo os princípios propostos por Panizzi, foi a solução em uma determinada época. Mas, como defendeu Lubetzky (1979), o processo intelectual adotado para fundamentar a catalogação não pode ser substituído pelas inovações tecnológicas que visam unicamente aperfeiçoar a maneira de confeccionar os registros. Portanto, o modelo conceitual FRBR fornece um conjunto de elementos semânticos compatíveis com os mais sofisticados recursos tecnológicos, o que proporciona uma maior precisão, agilidade e clareza aos processos biblioteconômicos, sendo a recuperação de informações o mais favorecido.

Em vista disso, não se pode deixar de fazer menção às possibilidades que o modelo conceitual FRBR traz quando associado à tecnologia da Web Semântica. Pensado a partir dos conceitos entidades, atributos e relacionamentos, ele ultrapassa a questão da estruturação dos dados dentro do registro bibliográfico e abre a possibilidade para que se possa criar um vocabulário FRBR, de modo que os agentes de softwares possam identificar as entidades bibliográficas no universo Web.

A descrição dos metadados em RDF ${ }^{5}$ numa sintaxe mais próxima da linguagem do usuário, como

\footnotetext{
4 "[...] the only kinds of records in the catalogue were entries and references. Panizzi had three kinds of references: 1) name to name, 2) name to work, and 3) work to work. Bibliographic records were essentially entered only once and access to those records was provided through references [...] The single full entry with brief references to it was the most economical structure for the catalogue. At the turn of the twentieth century [...] the cataloguing rules responded with a new devices, called the added entry, which could be made by typing and added heading at the top the pre-printed main card [...]".

5 Segundo Feitosa (2006, p.101), "o RDF (Resource Description Framework) é um esforço para a criação de convenções que controlem como a semântica, a sintaxe e a estrutura de metadados são formuladas em um domínio, de modo que, quando tais estruturas forem misturadas com um segundo ou terceiro domínio, as declarações originais mantenham sua clareza e legibilidade".
} 
propõe a $\mathrm{RDA}^{6}$, permitirá que o acesso à informação ocorra de forma mais simples e autônoma. Nesse contexto a Web deixa de ser um depósito de dados e torna-se de fato um repositório universal, tal como preconizou Otlet ao idealizar o RBU.

São funções dos metadados no contexto Web descrever os recursos e permitir que suas informações sejam agenciadas pelos computadores e robôs de busca, para que eles compreendam os metadados associados aos documentos e assim possam recuperá-los, avaliá-los e manipulá-los com eficiência. Essa é uma das questões mais importantes na atual economia da informação, pois, conforme Marcondes (2013, p.15):

[...] Sistemas de Organização do Conhecimento, como sistemas de catálogos e repositórios digitais [...] são ainda calcados no modelo textual linear, para leitura por pessoas. Padrões utilizados, como o MARC e ISAD(G), são antigos e exclusivos, não são interoperáveis com os novos padrões surgidos com o projeto da Web Semântica. Além disso, metadados e documentos, como um registro MARC referenciando um documento digital num sistema de catálogo, são mantidos "prisioneiros" destes sistemas, isolados do resto da Web, só adquirindo significado dentro do contexto destes SOCs, quando são armazenados, recuperados e exibidos.

Outra questão importante em relação aos metadados é que na Web as publicações crescem de forma exponencial e não há profissionais suficientes para descrever essa massa informacional. Por isso, o desenvolvimento de padrões e formatos de metadados que permitam os autores publicarem e descreverem seus documentos "na fonte" é fundamental para se democratizar o acesso ao conhecimento, sonho esse perseguido pela Documentação, como preconizaram Paul Otlet e La Fontaine ao idealizarem o Repositório Bibliográfico Universal (RBU).

Conforme Mey (1995, p.6), "a riqueza da catalogação repousa nos relacionamentos entre os itens estabelecidos, de forma a criar alternativas de escolha para os usuários". Ou seja, ao consultar um catálogo (base de dados), o usuário poderá escolher entre diferentes versões ou suportes, conhecer as manifestações de um mesmo item (livro impresso, digital etc.), bem como suas diferentes edições, traduções e línguas, o que Ihe garantirá durante o processo de recuperação da informação uma busca mais rica e ampla.

No entanto, para que isso ocorra, os códigos de catalogação, vocabulários e tesauros deverão ser formatados dentro dos padrões propostos pelo W3C para a Web Semântica. Ou seja: "cada elemento de descrição devem ser representado em declarações RDF" para que seja legível por máquinas (Catarino \& Souza, 2012, p.85). Essa necessidade vem levando a área de catalogação descritiva a rever seus paradigmas, sendo o desenvolvimento do modelo conceitual FRBR a ação mais significativa para atingir o objetivo e, de forma rápida e fácil, dar visibilidade e acesso aos recursos escondidos nos bancos de dados bibliográficos submersos na Web. Por isso, além da elaboração de modelos conceituais para estruturar os dados, seus conteúdos devem ser descritos na linguagem XML, um padrão universal referendado pelo W3C, voltado "para a descrição da estrutura de documentos eletrônicos onde o conteúdo e sua descrição compõem um único arquivo, de tipo texto puro, portável, portanto, sem problemas para qualquer tipo de sistema computador [...]" (Marcondes, 2005, p.104).

[...] Ao contrário de outros formatos de arquivos [...] um arquivo XML não está preso a um programa para lê-lo; na XML são explicitados, além dos conteúdos dos documentos, a sua estrutura, sob a forma de marcações, identificadas por um nome significativos, envolvido nos caracteres" $<$ " e">"; a cada marcação indicando o início de um determinado conteúdo, por exemplo <autor>, corresponde uma marcação de fim, </autor $>$; os conteúdos ficam entre marcações, < autor> João da Silva</autor> (Marcondes, 2005, p.104).

Segundo Catarino e Souza (2012, p.86), é necessário modelar os dados já existentes que se utilizam de MARC ou Dublin Core nos moldes do RDF, bem como escrever os vocabulários controlados existentes em linguagens propostas pelo W3C (ontologias), ou seja, expressar a semântica internalizada em suas descrições para que programas especiais, os chamados "agentes

\footnotetext{
${ }^{6}$ A Resource Description and Access (RDA) é o novo padrão de Catalogação para a descrição de recursos informacionais e irá, paulatinamente, substituir o Código de Catalogação Anglo-Americano, 2a edição (AACR2). Foi estruturada para o ambiente digital ese relaciona com as entidades do modelo conceitual FRBR (obra, expressão, manifestação e item) e tem como princípio norteador as tarefas do usuário (encontrar, identificar, selecionar, obter) (Oliver, 2011).
} 
inteligentes", acessem o conhecimento ali embutidos e, através de processo de inteligência artificial, sejam capazes de realizar tarefas (inferências) que demandem raciocínio e dedução.

Movida por esse pensamento é que a IFLA reviu a Declaração dos Princípios Internacionais de Catalogação (International Federation of Library Associations and Institutions, 2009). Seus fundamentos apontam para a construção de ferramentas para o tratamento e organização da informação (modelos, códigos, formatos, etc.) de acordo com a conveniência do usuário, ressaltando que o catálogo deve ser um instrumento efetivo e eficiente que permita encontrar recursos bibliográficos em uma coleção com o resultado de uma busca usando atributos e relações entre recursos. Tal ação serve para levantar itens de interesse dos usuários (resposta às pesquisas) como também para utilizar registros já elaborados, evitando duplicidade de esforços. Esses pressupostos retomados pela IFLA remontam às ideias de teóricos como Paul Otlet e sua tese sobre o Princípio Monográfico, uma das bases para se pensarem modelos conceituais para o domínio bibliográfico.

Em termos descritivos, o modelo conceitual FRBR recupera o princípio monográfico, pois separa a obra e suas expressões de suas manifestações. Ou seja, a obra é a referência comum. Numa descrição em FRBR, o ponto de partida não é o documento concreto, mas uma abstração: a obra, sendo o documento propriamente dito a obra produzida.

A modelagem de dados"é o processo de criação de uma estrutura de dados eletrônica (banco de dados) que contém as informações representadas do recurso a ser modelado"(Fusco, 2011, p.89). Essa estrutura permite ao usuário recuperar dados de forma rápida e eficiente. O modelo conceitual é o que realiza o design do sistema, pautado no domínio para o qual o mesmo está sendo desenvolvido, de modo a descrever os elementos que deverão ser modelados e prever como eles se relacionarão uns com os outros.

No âmbito da catalogação, o modelo conceitual FRBR foi a primeira iniciativa para a uniformização da maneira de realizar a modelagem conceitual das ferramentas bibliográficas, catálogos e repositórios. O modelo FRBR foi inspirado na modelagem entidade-relacionamento (E-R), e sua implementação se deu no plano conceitual. "Como todo modelo ele descreve um domínio composto por coisas, representadas pelas entidades; tais entidades possuem características a serem descritas, chamadas de atributos; e pelos relacionamentos existentes entre as entidades" (Silva \& Santos, 2012, p.9).

Como chamam a atenção Silva e Santos (2012), o modelo foi criado para o universo bibliográfico e isso obrigou seus desenvolvedores a realizar certas modificações na forma de apresentação dos conceitos pertinentes à sua construção, o que levou os críticos a relativizar a consistência de algumas entidades e a apontar ambiguidades na definição de suas categorias, já que o referente máximo (a obra) não tem sua materialidade expressa em sua própria natureza e sim em suas manifestações. Para entender os limites e as possibilidades de uso do modelo conceitual FRBR para a modelagem dos domínios bibliográficos, buscou-se ajuda na tese de Paul Otlet sobre o Princípio Monográfico.

\section{O modelo conceitual FRBR e as contribuições de Otlet}

Ao retomar o Princípio Monográfico, a ideia de Paul Otlet era a de categorizar a informação no seu nível mais elementar, e não apenas descrever partes informacionais como fazia a Bibliografia. O objetivo era extrair do texto aquilo que fosse considerado novo e informativo, a fim de compor um novo documento, ou melhor, uma nova unidade autônoma de informação, em que a descrição dos elementos intelectuais e o suporte físico fossem compatíveis (Santos, 2007).

Na obra Traité de Documentation (1934), Paul Otlet destina o quarto capítulo, Organisation rationnelle des livres e des documents, à apresentação do sistema de informação que desenvolvera e, assim, normatiza a Documentação. Nesse capítulo, "trata dos princípios que constituirão uma enciclopédia documentária ou o livro universal" (Santos, 2007, p.56). Dentre as observações de Otlet quanto a esses princípios, destacam-se seus esclarecimentos a respeito do Princípio Monográfico, entendido como o momento em que "cada elemento intelectual de um livro é (depois de ser seccionado do 
conjunto do texto) incorporado num elemento material correspondente" (Otlet, 1934, p.385, tradução nossa) ${ }^{7}$.

Dessa forma, observa que os livros e demais documentos científicos apresentam descobertas que geralmente se repetem; então, seria necessário sintetizar essa informação de modo a possibilitar sua recuperação de forma rápida e precisa, como também sua associação a outros documentos que tratassem do mesmo assunto. Para tanto Otlet (1934) recorre a outros dois princípios e reforça sua proposta em favor da objetivação da informação, de modo a economizar o tempo do leitor e suprimir as reiterações, sintetizando então o conhecimento. Desse modo, ao pensar as bases para a criação do repertório universal, acrescenta ao princípio da unidade documentária (Princípio monográfico) outros dois princípios:

a) o Princípio da continuidade e da pluralidade da elaboração, que consistia na redação de fichas analíticas, com campos de dados padronizados que serviam para acrescentar dados objetivos sobre o texto analisado, tais como autoria, título, etc., que indicassem a origem da informação tratada;

b) Princípio da multiplicação dos dados que consistia na duplicação das fichas de acesso à informação intercalando-as sob as rubricas das várias facetas da CDU. Esse procedimento possibilitava o acesso à informação por vários pontos de acesso do sistema (Santos, 2007, p.56, grifos do autor).

Os instrumentos documentários desenvolvidos por Otlet durante seu trabalho no Instituto Internacional de Bibliografia (IIB) como, por exemplo, a tecnologia das fichas padronizadas e a Classificação Decimal Universal (CDU), tiveram importante aplicação no desenvolvimento desses princípios, à medida que ampliaram, sob a ótica das bibliografias, os fundamentos do catálogo desenvolvidos por Panizzi na metade do século XIX. Vale ressaltar que o procedimento de duplicação das fichas tem proximidade com a tecnologia dos catálogos, ao possibilitar novas formas de acesso. A CDU, por ser uma estrutura lógica, serviria tanto para armazenar quanto para recuperar a informação. Santos (2007, p.56) adverte que "o Princípio Monográfico, se aplicado de forma ingênua, poderia provocar a dispersão da informação"; portanto, para se evitar esse problema era necessário recorrer a uma estrutura lógica de organização de informação como a CDU, pois,

[...] pela aplicação dos diferentes princípios propostos pela documentação, promoveria o mapeamento de todo o conhecimento produzido pelo homem. Por meio da objetivação e contextualização da informação, segundo Otlet, seriam criados novos discursos, do ponto de vista do próprio sistema. Em contrapartida, o sistema poderia oferecer várias possibilidades de acesso às informações, já que o discurso, fragmentado e tratado pelas tabelas da CDU, poderia ser recontextualizado pelo pesquisador. Otlet estava, na verdade, tentando escrever um novo tipo de livro, aquele que seria lido por toda a humanidade (Santos, 2007, p.56).

Para Otlet, (1934) a criação do Livro Universal, onde estaria contido todo o conhecimento do mundo, jamais estaria completa, dada a sua dinâmica de repositório universal. Sua estrutura seria oferecida ao usuário/ pesquisador para que através de pontos de acesso firmasse relacionamentos entre as obras e seus respectivos assuntos, o que possibilitaria economia de tempo e estimularia novas formas de leitura mais próximas dos processos mentais humanos.

Sob esse aspecto, pode-se dizer que o Princípio Monográfico proporciona uma nova maneira de organizar saberes, ou seja, um sistema que descreve elementos considerados úteis e omite elementos considerados inúteis. Ou, conforme as palavras de Otlet (1934, p.25, tradução nossa) na analogia com a metalurgia, que se utiliza de um método para "separar da ganga os minerais cuja rotulação é mais ou menos elevada"8, assim, da mesma forma, ao se aplicar a metodologia referente a esse princípio, poder-se-ia construir uma nova unidade intelectual.

Conforme relatam Maimone et al. (2011), o Princípio Monográfico propõe desobstruir a informação: independentemente da estrutura ou forma em que esteja, o seu conteúdo intelectual deverá ser recuperado. Por isso ao organizar a informação deve-se ter em mente

\footnotetext{
7 "[...] Chaqueélément intelectuel d'un livreest (après avoirété sectionné de l'ensemble du texte) incorporéen un élément matériel correspondant".

8 "[...] le problèma n'est pas sans analogie avec celui de la métallurgie, qui a pour objet une méthode pour séparer de la gangue les minerais dont le titrageest plus ou moinsélevé".
} 
o fundo e a forma, pois se desconsiderá-los haverá dispersão dos dados no sistema. Nessa direção as autoras ressaltam que:

[...] Nos FRBR o princípio monográfico proposto por Otlet parece "ganhar vida", quando separa o documento em quatro entidades distintas: obra, expressão, manifestação e item. As duas primeiras possuem características independentes de seus suportes e as duas últimas apresentam as características relacionadas ao suporte, ou seja, o princípio monográfico é aplicado também na representação descritiva (Maimone et al., 2011, p.30).

Ao trabalhar com a fragmentação do suporte (aná lise) e a totalidade (síntese), Otlet reorganiza a informação sob um novo formato bibliográfico, o repertório. Surge, então, uma nova unidade de conteúdo que, mediada por pontos de acesso e pela classificação universal, otimiza a recuperação do conhecimento acumulado e facilita a obtenção de diversos materiais.

Os recursos informacionais organizados segundo esse princípio assemelham-se aos registros das bases de dados e aos objetos hipertextuais, pois são unidades de informação que podem ser compreendidas isoladamente, isto é, podem ser reinterpretadas e relacionadas de diversas maneiras segundo os objetivos do pesquisador. A unidade informacional pode ser associada a uma diversidade de unidades que tratem do mesmo assunto, proporcionando economia de tempo e precisão na recuperação da informação (Santos, 2007).

\section{Procedimentos metodológicos}

Esta é uma pesquisa exploratória de caráter histórico e documental, que visa averiguar os pressupostos clássicos da representação da informação, relacionandoos com o contexto da Web Semântica e, mais especificamente, com as bases teóricas que fundamentam o modelo conceitual FRBR para a representação de conteúdos em ambiente digital. Também se procura analisar como esse novo paradigma da catalogação se aproxima do princípio da unidade documental tal como preconizou Paul Otlet ao idealizar a bibliografia universal. Para isso, recorreu-se ao Repositório Acesso Livre à Informação Científica da Embrapa (ALICE) desenvolvido pela Empresa
Brasileira de Pesquisa Agropecuária (EMBRAPA) em 2011 utilizando o software livre DSPACE e o Dublin Core para a descrição dos recursos digitais, padrões adotados pela comunidade científica mundial e interoperáveis com os demais sistemas de acesso aberto. Sua função é reunir, organizar, armazenar, preservar e disseminar, na íntegra, informações científicas produzidas por seus pesquisadores em capítulos de livros, artigos de periódicos indexados, anais de congressos, teses e dissertações, notas técnicas, dentre outras produções (Empresa Brasileira de Pesquisa Agropecuária, 2014).

Apesar do pouco tempo de existência, ALICE reúne 16 mil documentos e é um dos repositórios mais consultados em todo o Brasil, registrando anualmente grandes quantidades de acesso e downloads. Sua escolha como campo empírico se deu em função de sua vitalidade junto à comunidade científica, sendo referência para a divulgação da pesquisa agropecuária no Brasil e no mundo; suas coleções contemplam na íntegra diferentes expressões e manifestações de um amplo espectro de estudos científicos.

São oferecidas aos usuários duas estratégias de busca: busca simples e avançada. Para refinar a pesquisa, são oferecidos filtros de busca por assunto, título, autor, data de envio do documento e tipologia.

A pesquisa consistiu em identificar no Repositório ALICE, através de levantamento e seleção, o registro de versões distintas de uma obra. Foi realizada busca simples sobre o assunto "bicombustível" e encontradas duas ocorrências para obras dos autores Campos, C.G.; Ribeiro, J.A. de A.; Costa, P.P.K.G.; Rodrigues, C.M.; Abdelnur, P.V. (Figura 1).

Foram recuperados dois registros de documentos que apresentavam as seguintes características: mesma autoridade e título, informações básicas para identificar expressões de uma mesma obra manifestas sob formas diferentes. Assim, foi selecionado o registro de um artigo científico que apresentava duas versões para download, ambas em formato PDF, sendo uma o resumo e a outra o pôster do artigo apresentado em Congresso. Isso deu subsídios para as pesquisadoras simularem a aplicação das bases teóricas que fundamentam o modelo conceitual FRBR, associando-o aos princípios definidos por Otlet (1934). 


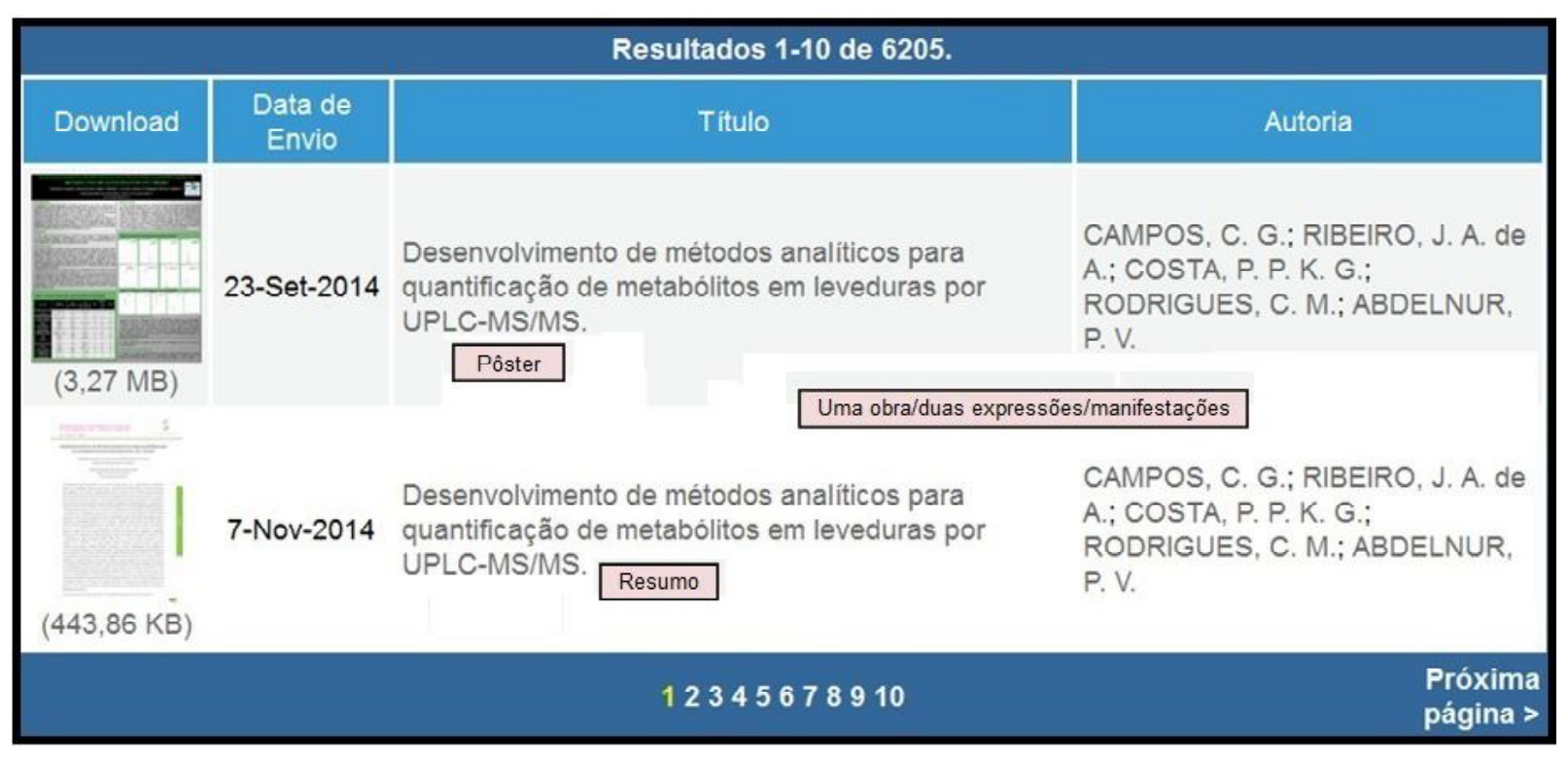

Figura 1. Resultado da busca.

Fonte: Elaborada pelas autoras (2015).

\section{Resultados e Discussão}

Quando simulada a aplicação do modelo conceitual FRBR em repositório bibliográfico, pode-se visualizar e entender com maior propriedade os fundamentos estabelecidos por Otlet (1934) com o Princípio Monográfico. Através dos relacionamentos, foi possível identificar diferentes expressões e manifestações de um documento, ou seja, unidades documentárias distintas cujo conteúdo intelectual se apresenta sob nova forma física (tipologias documentais) e sob novas abordagens, no que diz respeito a diferentes aspectos, como obra original, resumo, versão, adaptação etc. No exemplo acima (Figura 1) tem-se a obra Desenvolvimento de métodos analíticos para quantificação de metabólicos em leveduras por UPLC-MS/MS, com duas ocorrências no Repositório ALICE, ou seja, duas expressões distintas da mesma obra (um artigo científico) ora manifestada como pôster apresentado no Congresso (CNPAE), ora manifestada como resumo publicado nos anais do Congresso (CNPAE), ambas depositadas em 2014. Essas duas ocorrências, de acordo como o modelo conceitual FRBR, revelam duas expressões e manifestações de uma mesma obra, ou seja, unidades documentárias distintas e que são parte de um mesmo todo: a coleção CNPAE, que por sua vezé parte de um todo ainda maior, o repositório.

Esse exemplo revela que há forte identidade entre as entidades do Grupo 1 dos FRBR (obra, expressão, manifestação e item) e os princípios elencados por Otlet para a organização de um repertório: o Princípio Monográfico (todo-parte) e os Princípios da Continuidade e da Pluralidade, expressos na descrição analítica do conteúdo dos documentos, conforme demonstram as Figuras 2 e 3.

Indo ao encontro da proposta dos repositórios, o objetivo do modelo conceitual FRBR é permitir que, a partir de uma única busca, todos os registros relacionados a uma unidade bibliográfica, categorizada de acordo com o modelo como obra ou expressão, sejam exibidos ao usuário para que possa selecioná-los de modo a responder à sua questão de pesquisa.

A nova estruturação de dados (Figura 4) prima por identificar através de atributos as entidades, tornando-as únicas no universo digital para que, livres de ambiguidades, possam ser recuperadas pelos computadores e seus agentes (softwares de busca), conforme demonstra o figura a seguir que simula a aplicação do modelo conceitual FRBR na estrutura descritiva do 


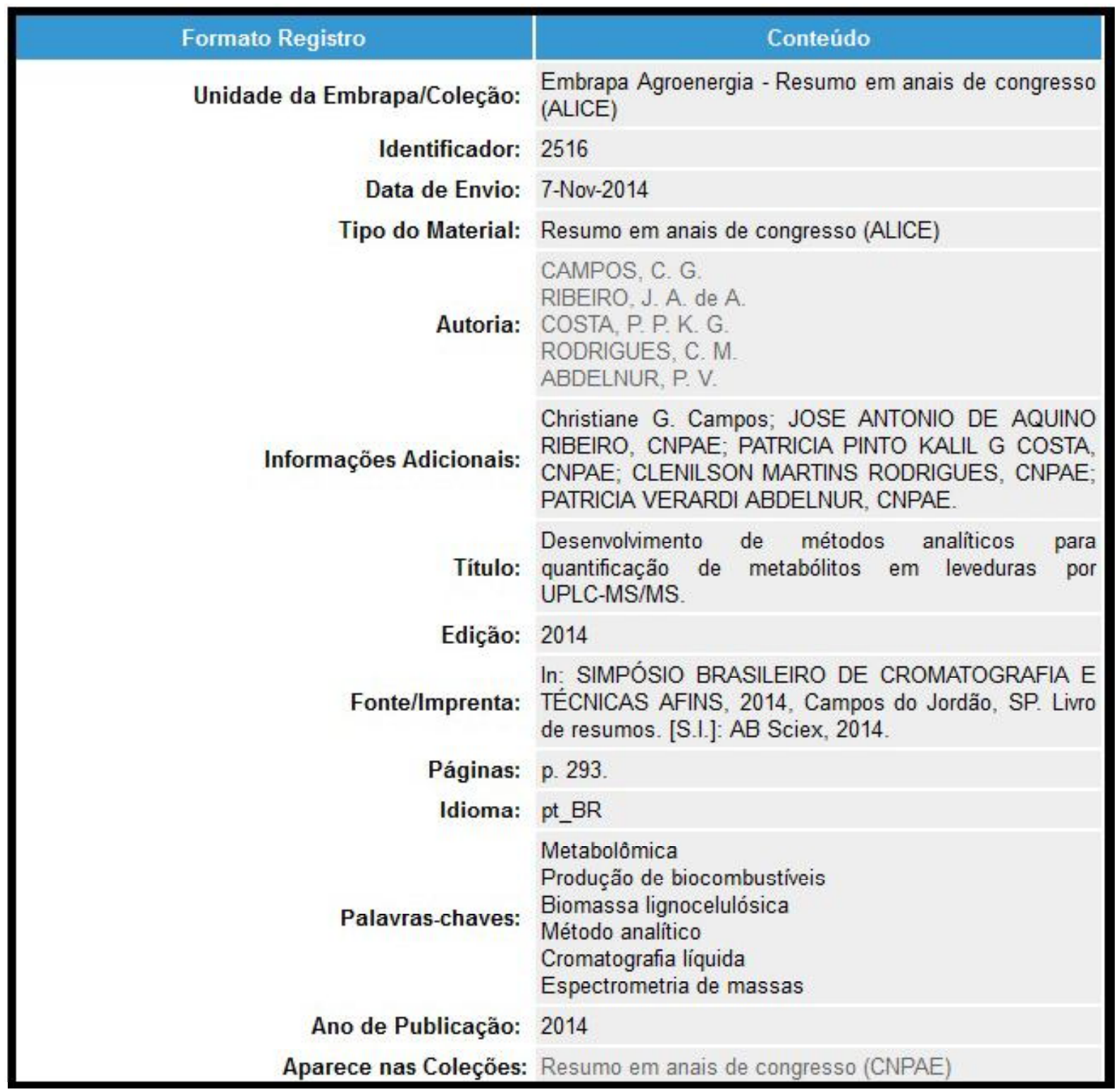

Figura 2. Metadados Dublin Core do resumo do artigo.

Fonte: Empresa Brasileira de Pesquisa Agropecuária (2014).

Repositório ALICE e sua relação com os princípios de Paul Otlet.

A definição criteriosa dos atributos de cada entidade é fundamental para garantir a consistência da busca. Sob esse aspecto o modelo conceitual FRBR facilita as "tarefas dos usuários", relacionando todos os metadados descritos de forma coordenada e superando os limites da antiga estrutura (ISBD), que previa uma descrição hierarquizada. No que diz respeito às descri- ções, estas passam a ser extensas e sem simplificações, aproximando-se de fato da forma intuitiva de organização do pensamento humano.

Nesse contexto os metadados Dublin Core (DC) podem ser representados por diferentes sintaxes, "sendo comum a representação no formato HTML, RDF usando XML e em formatos genéricos do tipo Elemento = valor, podendo seus elementos estar dentro do recurso ou separado deles" (Grácio, 2002, p.84). 


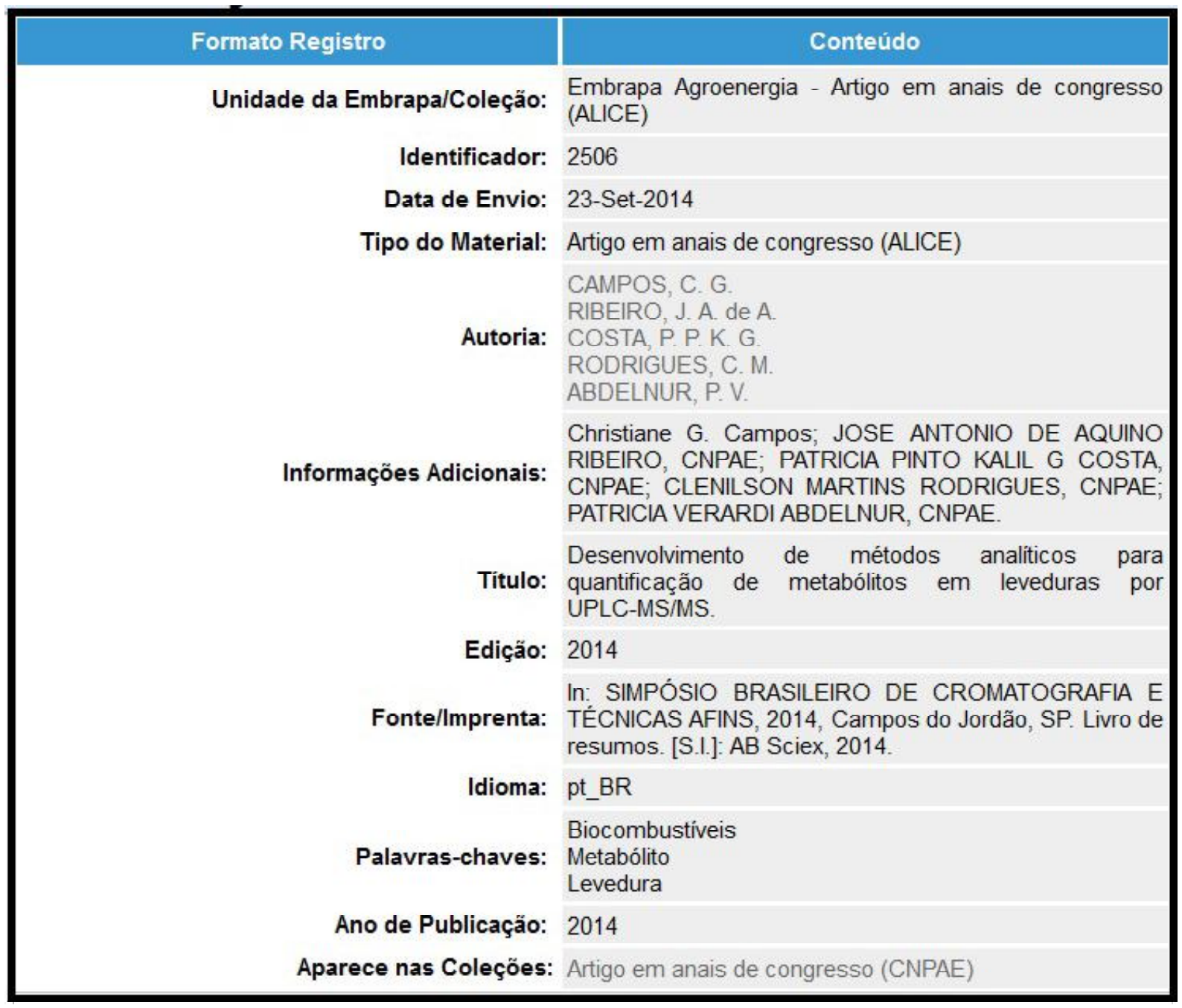

Figura 3. Metadados Dublin Core do pôster do artigo.

Fonte: Empresa Brasileira de Pesquisa Agropecuária (2014).

\section{Conclusão}

Como observado, as práticas da representação descritiva estão diretamente relacionadas com a proposta de organização dos recursos no contexto da Web Semântica, o que levou a IFLA a rever os princípios da catalogação e introduzir um novo modelo conceitual, os FRBR, cujos fundamentos retomam conceitos clássicos da organização da informação, conforme preconizaram Panizzi e, mais especificamente para o âmbito da documentação, Paul Otlet.

Dessa forma, na atualidade, o modelo conceitual FRBR retoma o conceito de obra proposto por Panizzi, como parte dos princípios para a produção de catálogos em bibliotecas, e de unidade documentária, para a descrição de recursos em repositórios com a finalidade de agrupar todas as "manifestações" e as "expressões" de uma mesma obra, de modo a permitir ao usuário selecionar aquela que melhor corresponda às suas necessidades informacionais.

O princípio monográfico retomado por Otlet em seu Tratado de Documentação introduziu uma nova maneira de organizar os saberes de forma mais flexível, permitindo a inserção de elementos considerados importantes para a recuperação das informações conforme a necessidade do usuário, mostrando que, além dos tradi- 


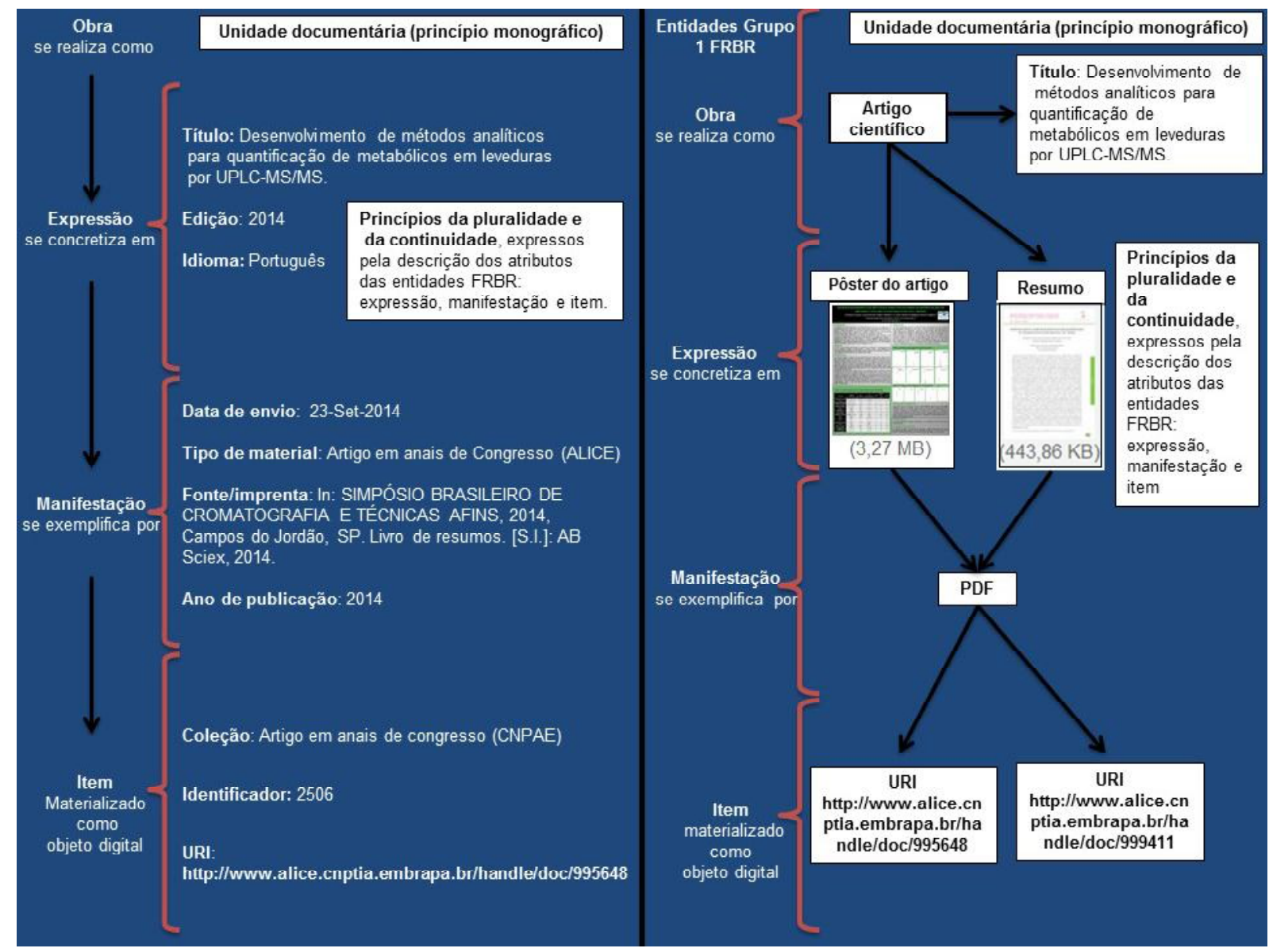

Figura 4. Modelagem (entidades do grupo 1 do modelo conceitual FRBR). Relação com os princípios de Otlet. Fonte: Elaborada pelas autoras (2015).

<title> Alice: Desenvolvimento de métodos analíticos para quantificação de metabólitos em levedutas por UPLC-MS/MS. </title>/><meta name="DC.creator" content="CAMPOS, C. G." xml:lang="pt_BR" /><meta name="DC.creator" content="RIBEIRO, J. A de A." xml: lang="pt BR" / > meta name="DC.creator" content="CosTA, P. P. K. G." xml:lang="pt BR"/><meta name="DC. creator" content="RODRIGUES, C. M." XML: lang="pt $B \bar{R} " /></$ meta name="DC.creator" content="ABDELNUR, P. V." XML: lang="pt $\overline{B R} " /$

Figura 5. Metadados Dublin Core.

Fonte: Empresa Brasileira de Pesquisa Agropecuária (2014).

cionais pontos de acesso, a estrutura de relacionamentos oferecia economia de tempo e estimulava novas formas de leitura, mais próximas aos processos mentais do usuário. Tal conceito foi potencializado com a criação dos FRBR, pautados no modelo computacional E-R (entidade/relacionamento).
Para ilustrar como a tese de Otlet se aplica às bibliografias contemporâneas, os chamados repositórios, foi exibida a simulação de modelagem realizada no repositório ALICE, relacionando-as com os Princípios Monográfico, da Continuidade e da Pluralidade, de modo a demonstrar como estes se expressam nas entidades 
do Grupo 1 do modelo conceitual FRBR. Isso revela a atualidade das ideias do autor e como elas influenciaram a modelagem de dados, permitindo inclusive estender a aplicação do novo modelo conceitual às bibliografias digitais (repositórios), ferramentas estruturadas no formato Dublin Core e que trazem a vantagem de terem seus metadados descritos em RDF, o que potencializa a recuperação de suas informações pelos robôs de busca que vasculham a Web.

Essas ações têm caminhado no sentido de permitir que os dados bibliográficos contidos nos catálogos e repositórios possam ser inseridos em declarações nos moldes do RDF, o que permitirá num futuro bem próximo que cada entidade bibliográfica ganhe um identificador universal - URI -, transformando as bases de dados em dados lincados, o que permitirá ao usuário acesso a uma massa informacional há séculos estocada, tal como preconizou Otlet ao criar seu repertório universal.

Nessa direção, a organização dos dados (em catálogos ou em repositórios) de acordo como o modelo conceitual FRBR possibilitará ao usuário encontrar, através de uma única busca, diferentes expressões e manifestações de uma mesma obra, bem como identificar em quais locais pode adquiri-la ou acessá-la, caso seja um recurso digital. Será ainda possível verificar se o título buscado está disponível na biblioteca local ou em outras bibliotecas e livrarias, e ser informado sobre resenhas e grupos de discussão que abordam a temática, etc.

No caso dos repositórios, a criação de uma ontologia Dublin Core e a descrição dos metadados em linguagem RDF otimizam a busca da informação pelos agentes de softwares, ação esta que poderá se estender ao modelo conceitual FRBR com a criação de um vocabulário compatível. O estudo também mostrou que padrões consagrados, como o DC, podem sofrer modelagem (Figura 4) e suportam bem a expansão de suas estruturas com inserção de campos oriundos do modelo conceitual FRBR.

Enfim, há que ser ousado e se aventurar a expandir o modelo conceitual FRBR nos níveis lógico e físico, tomando como ponto de partida as experiências bem sucedidas dos repositórios estruturados em Dublin Core, cuja modelagem de dados suporta uma reestruturação nos moldes E-R sem perda de informação.

\section{Colaboradores}

Todos os autores contribuíram na concepção e desenho do estudo, análise de dados e redação final. Na configuração das imagens as autoras contaram com a colaboração de Wellington Freire Cunha Costa.

\section{Referências}

Barbosa, A.P. Novos rumos da catalogação. Rio de Janeiro: BNG, 1978.

Berners-Lee, T: Hendler, J.: Lassila, O. The semantic web: A new form of web content that is meaningful to computers will unleash of new possibilities. Scientific American, v.284, n.5, p.34-43, 2001. Available from: <http://www.scian.com/2001/ 0501 issue/0501 berners-lee.html>. Cited: May 24, 2001.

Catarino, M.E.; Souza, T.B. A representação descritiva no contexto da web semântica. Transinformação, v.24, n.2, p. 77-90, 2012. Disponível em: <http://www.scielo.br/scielo.php?script =sci_arttext\&pid=S010337862012000200001\&lng=en\&nrm=iso > . Acesso em: 10 jul. 2014.

Empresa Brasileira de Pesquisa Agropecuária. Repositório Alice: acesso livre à informação científica da Embrapa. 2014. Disponível em: <http://www.alice.cnptia.embrapa.br/>. Acesso em: 10 mar. 2014.

Feitosa, A. Organização da informação na web: das tags à web semântica. Brasília: Thesaurus, 2006.

Fiuza, M.M. A catalogação bibliográfica até o advento das novas tecnologias. Revista da Escola de Biblioteconomia da UFMG, v.16, n.1, p.43-53, 1987.
Fusco, E. Aplicação dos FRBR na modelagem de catálogos bibliográficos. São Paulo: Cultura Acadêmica, 2011.

Grácio, J.C.A. Metadados para a descrição de recursos da Internet: o padrão Dublin Core, aplicações e a questão da interoperabilidade. 2002. Dissertação (Mestrado em Ciência da Informação) - Faculdade de Filosofia e Ciências, Universidade Estadual Paulista, Marília, 2002.

International Council of Museums. FRBRoo introduction, 2009. Available from: <http://www.cidoc-crm.org/frbr_inro.html $>$. Cited: Mar. 10, 2014.

International Federation of Library Associations and Institutions. Functional requirements for bibliographic records: Final report. München: K.G. Saur, 1998. Available from: <http:// www.ifla.org/files/assets/cataloguing/frbr/frbr_2008.pdf>. Cited: Jun. 27, 2013.

International Federation of Library Associations and Institutions. Declaração de princípios internacionais de catalogação. 2009. Disponível em: <http://www.ifla.org/files/assets/ cataloguing/icp/icp_2009-pt.pdf >. Acesso em: 20 maio 2014.

Lubetzky, S. Ideology of bibliographic cataloguing: Progress and retrogression. In: Freedman, M.J.; Malinconico, S.M. (Ed.). 
The nature and future of the catalog: Proceedings of the ALA'S Information Sciences and Automation Division's 1975 and 1977 Institutes on Catalog. Phoenix: Oryx Press, 1979. p.5-13.

Maimone, G.D.; Silveira, N.C.; Tálamo, M.F.G.M. Reflexões acerca das relações entre representação temática e descritiva. Informação \& Sociedade: Estudos, v.21, n.1, p.27-35, 2011.

Marcondes, C.H. Organização e representação do conhecimento científico em ambiente WEB: do formato textual linear aos artigos semânticos. Ponto de Acesso, v.7, n.1, p.7-41, 2013. Disponível em: <http://www.portalseer.ufba.br/ index.php/revistaici/article/view/8134> Acesso em: 14 jul. 2014.

Marcondes, C.H. et al. (Org.) Bibliotecas digitais: saberes e práticas. Salvador: EDUFA; Brasília: IBICT, 2005. Disponível em: http://livroaberto.ibict.br/bitstream/1/1013/1/Bibliotecas\% 20Digitais.pdf Acesso: 10 jul. 2014.

Mey, E.S.A. Introdução á catalogação. Brasília: Briquet de Lemos/Livros, 1995.
Oliver, C. Introdução à RDA: um guia básico. Brasília: Briquet de Lemos/Livros, 2011.

Ortega, C.D. Do princípio monográfico à unidade documentária: exploração dos fundamentos da catalogação. Liinc em Revista, v.7, n.1, p.43-60, 2011.

Otlet, P. Traité de documentation: le livre sur le livre: théorie et pratique. Bruxelles: Mundaneum, 1934.

Santos, P. Paul Otlet: um pioneiro da organização das redes mundiais de tratamento e difusão da informação registrada. Ciência da Informação, v.36, n.2, p.54-63, 2007.

Silva, R.E.; Santos, P.L.V.A.C. Requisitos Funcionais para Registros Bibliográficos (FRBR): considerações sobre o modelo e sua implementabilidade. Revista Brasileira de Biblioteconomia e Documentação, v.8, n.2, p.116-129, 2012. Disponível em: $<$ http://rbbd.febab.org.br/rbbd/article/view/214>. Acesso em: 10 jun. 2014.

Tillett, B. Bibliographic relationships in library catalogues. International Cataloguing and Bibliographic Control, v.17, n.1, p.3-6, 1988 .
157

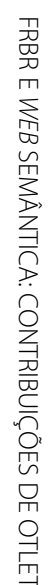


